\title{
EFFECT OF CHITOSAN ON RESIN-DENTIN INTERFACE DURABILITY: A 2 YEAR IN-VITRO STUDY
}

\begin{abstract}
Ahmed Zidan*
ABSTRACT

Aim: The aim of the current study was to evaluate immediate and long-term bonding effectiveness of chitosan-treated dentin, bonded using 2-step etch-and-rinse dental adhesive, after 2 years of ageing.

Materials \& Methods: Microtensile bond strength test and nanoleakage examination of resin-dentin interfaces, created by Adper Single Bond 2 with or without chitosan pre-treatment, were performed after 24 h, 12 mos and 24 mos of water storage. Stiffness of demineralized dentin sticks treated with chitosan for 1 or 10 min was evaluated. Matrix metalloproteinases (MMPs) activity was also assessed by measuring the amount of hydroxyproline release, indicating collagen degradation by MMPs, after chitosan treatment for 1 or $10 \mathrm{~min}$. Data were collected, tabulated and statistically analysed.

Results: Chitosan treatment of acid-etched dentin, before adhesive application, resulted in

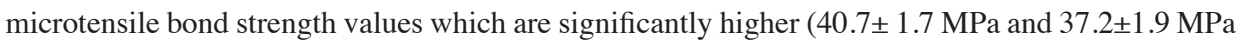
respectively) and nanoleakage values $(56.5 \pm 3.8 \%$ and $62 \pm 3.6 \%$ respectively) that are significantly lower than the untreated control group at $12 \operatorname{mos}$ and 24 mos storage periods $(\mathrm{P} \leq 0.05)$. The stiffness of demineralized dentin increased significantly after 1 min chitosan application (12.6 \pm 1.8 $\mathrm{MPa})$ and further increased after $10 \mathrm{~min}$ chitosan application $(22.4 \pm 2.2 \mathrm{MPa})$. Hydroxyproline released decreased significantly $(P$-value $<0.001)$ when completely demineralized dentin was treated with chitosan for $1 \mathrm{~min}(1.1 \mu \mathrm{g} / \mathrm{mg}$ dentin) with further significant decrease when chitosan was used for $10 \mathrm{~min}(0.8 \mu \mathrm{g} / \mathrm{mg}$ dentin).
\end{abstract}

Conclusion: Chitosan treatment of acid-etched dentin, before adhesive application, was effective in improving durability of resin-dentin bonded interfaces.

Clinical Significance: Despite of the great advances that have occurred in the field of adhesive dentistry, still, biodegradation of resin-dentin bonds over time continues to jeopardize the durability and success of resin composite restorations.

KEYWORDS: Chitosan, etch-and-rinse adhesive, dentin, microtensile bond strength, nanoleakage, stiffness, hydroxyproline release.

* Lecturer, Dental Materials Department, Faculty of Dentistry, October University for Modern Sciences and Arts (MSA). 


\section{INTRODUCTION}

There is a global consensus that resin-dentin bonds created with current hydrophilic dental adhesives deteriorate by time. ${ }^{1,2}$ Numerous studies have confirmed this finding by demonstrating rapid decrease in dentin bond strength with time, using both etch-and-rinse and self-etch dental adhesives. ${ }^{2-4}$ This problem is related mainly to resin-dentin bonds, since enamel bonds are proved to be highly stable. ${ }^{5}$

Improper resin infiltration of the demineralized exposed dentinal collagen, increased permeability of resin-dentin interface and activation of matrix metalloproteinases (MMPs) and cysteine cathepsins are some of the factors that are responsible for collagen and resin degradation and consequently adversely affecting the durability of the bonded interface. $^{1-4}$

Degradation of the dentinal collagen by MMPs and cysteine cathepsins plays a major role in the degradation of the bonded interface. Many MMPs and cysteine cathepsins were detected in dentin and were assumed to be responsible for the destruction of any exposed collagen within the bonded interface. Recently, the mechanisms of proteolytic degradation of resin-dentin interface has greatly attracted the attention. Since then, many scientists and clinicians have introduced several methods or treatment modalities to improve the durability of dentin bonded interfaces. ${ }^{8}$ These endogenous dentin proteolytic enzymes are bound to collagen fibrils and trapped by hydroxyapatite crystals. ${ }^{9}$ Acid-etching causes dentin demineralization, exposing these enzymes which become activated and ready to digest exposed collagen. Moreover, subsequent application of acidic monomers, present in etch-and-rinse or self-etch adhesives, further activate these proteolytic enzymes. ${ }^{10-14}$ Several strategies were introduced to overcome this problem, either to inhibit MMPs and cysteine cathepsins or inactivate them, to improve the stability of dentin-bonded interfaces. Inhibition of these dentinal enzymes was done us- ing MDPB, EDTA, Chlorhexidine or Chlorhexidine methacrylate. ${ }^{15-18}$ On the other hand, inactivation of MMPs was performed by increasing the collagen resistance to hydrolytic degradation by reinforcing and stabilizing the collagen fibrils through inter- and intramolecular cross-linking. ${ }^{19-21}$ Cross-linking of collagen was done by using different cross-linking agents as formaldehyde, grape seed extract, glutaraldehyde, carbodiimide, transglutaminase, proanthocyanidin, genepin, and riboflavin..$^{22-27}$

Chitosan is a natural biocompatible polymer. It is capable of forming a fibrillar network, with superior mechanical properties, at micro and/or nano-scale. Chitosan was used as a reinforcement phase of collagen scaffolds in the tissue engineering field. ${ }^{28}$ Several studies, that used chitosan together with other crosslinking agents, demonstrated an increase in the mechanical properties and in the degradation resistance of dentin. ${ }^{28-30}$ In addition, chitosan has a wide range of antibacterial activity and was claimed to increase dentinal surface wettability which may provide a great advantage if used to treat the demineralized dentin prior to adhesive application. ${ }^{31,32}$

Due to its outstanding properties, modification of demineralized dentin using chitosan could be of great importance in dentin bonding. Although previous studies ${ }^{22-30}$ have proved the importance of collagen network strengthening in providing a more stable and durable bonded interface, the effect of chitosan on dentinal collagen has not been fully investigated yet.

Therefore, the objective of the present study was to evaluate immediate and long-term bonding effectiveness of chitosan-treated dentin, bonded using 2-step etch-and-rinse adhesive, after 2 years of ageing. The null hypotheses tested were that (i) Chitosan treatment does not affect the immediate dentin bond strength and nanoleakage, (ii) Chitosan treatment does not affect the degradation of the resin-dentin interface over time. 


\section{MATERIALS AND METHODS}

\section{Specimen preparation for microtensile bond strength test and nanoleakage examination}

Twenty four sound extracted human molars were selected and used in this study. The teeth were collected from young patients (18-22 y) with signed consent according to a protocol approved by the Research Ethics Committee of Umm AlQura University, Mekkah, Saudi Arabia. The teeth were stored, not more than one month, in $0.5 \%$ chloramine T solution at $4^{\circ} \mathrm{C}$.

Each tooth was cut occlusally at $90^{\circ}$ to its long axis, removing the enamel and the superficial dentin, using a low speed diamond saw (Allied High Tech Products Inc.) with water coolant. Dentin surfaces were polished using a wet 320 grit silicon carbide (SiC) paper to standardize the created smear layer. The prepared specimens were randomly divided into 2 groups ( $\mathrm{N}=12$ teeth in each group). In Group I: acid-etched dentin surfaces were bonded directly with Adper Single Bond 2 (3 M ESPE, St. Paul, MN, USA), i.e. control group (received no pretreatment before adhesive application). In Group II: Chitosan solution was applied on etched-dentinal surfaces, then Adper Single Bond 2 adhesive was applied.

Acid-etching of dentinal surfaces was performed for $15 \mathrm{sec}$ using 35\% phosphoric acid gel (3 M ESPE, St. Paul, MN, USA), followed by $10 \mathrm{sec}$ rinsing and gentle drying (leaving a moist surface without pooling of water). Two coats of Adper Single Bond 2 adhesive was then applied to etched dentin for $15 \mathrm{sec}$ with mild scrubbing action. Gentle airdrying for $5 \mathrm{sec}$ is done, then light curing for $10 \mathrm{sec}$ took place (LED curing unit, 3M ESPE, Germany, $\left.1200 \mathrm{~mW} / \mathrm{cm}^{2}, 430-480 \mathrm{~nm}\right)$. In the second group, the chitosan solution $(0.1 \mathrm{~mol} / \mathrm{L}$ acetic acid $)$ was generously applied on the etched-dentinal surface, kept for $60 \mathrm{sec}$ and then gently dried, followed by adhesive application as previously mentioned.

Resin composite (Filtek Z350 XT, 3M ESPE) build-up is performed using the incremental packing technique. The prepared specimens were stored in $37^{\circ} \mathrm{C}$ water for $24 \mathrm{~h}$, then each tooth was cut into 16 sticks $(0.9 \times 0.9 \mathrm{~mm})$ using the non-trimming technique. ${ }^{33}$ The sticks obtained from each tooth were placed in separate containers. Each group (12 teeth) was divided into three storage subgroups ( $\mathrm{n}=4$ teeth): $24 \mathrm{~h}\left(\mathrm{~T}_{0}\right)$ or $12 \operatorname{mos}\left(\mathrm{T}_{12}\right)$ or $24 \operatorname{mos}$ $\left(\mathrm{T}_{24}\right)$ storage in distilled water at $37^{\circ} \mathrm{C}$. Every tooth provided 15 sticks for microtensile bond strength test and one stick for nanoleakage examination.

\section{Microtensile bond strength evaluation}

After storage according to each subgroup, a digital caliper was used to measure the dimensions of each stick. A microtensile testing machine (Bisco Inc.), at a crosshead speed of $1 \mathrm{~mm} / \mathrm{min}$, was used to stress each stick under tension. The tensile force at failure was recorded and then was divided by the cross-sectional area of each stick to calculate the microtensile bond strength (MPa). The mean of the bond strength values of the 15 sticks was calculated to give a value for each tooth. Then, a grand mean was obtained from the values of the 4 teeth of each storage group (the statistical unit is the tooth and not the stick).

\section{Nanoleakage evaluation}

Two layers of nail varnish was used to coat the stored bonded dentin sticks, leaving $1 \mathrm{~mm}$ from the interface without coating. The sticks were then immediately stored for $24 \mathrm{~h}$ in a $50 \mathrm{wt} \%$ ammoniacal silver nitrate $\left(\mathrm{AgNO}_{3}\right)$ solution with a $\mathrm{pH}=9.5$. The sticks were removed, water-rinsed and then immersed for $8 \mathrm{~h}$ in a photodeveloper under fluorescent light. SiC papers of increasing fineness (600-1200 grit) were used to polish the specimens. Then the specimens were cleaned in an ultrasonic cleaning system for $30 \mathrm{~min}$. Resin-dentin interfaces were examined by an environmental scanning electron microscope (Quanta 200 ESEM, France), using backscattered mode at 1000X. The amount of silver nitrate precipitated within the interface was 
quantitated using an image analysis software (NIH Image, USA). ${ }^{34}$

\section{Specimen preparation for stiffness evaluation and hydroxyproline release tests}

Sound extracted third molars, collected and stored as previously mentioned, were used. A dentin disc, with $0.5 \mathrm{~mm}$ thickness, was obtained from each tooth using a Techcut 4 diamond saw (Allied High Tech Products Inc.). A total of 60 dentin sticks $(3 \times 6 \mathrm{~mm})$ were cut from these discs. Complete demineralization of the sticks was done by vibrating the sticks in sealed containers, having $10 \%$ phosphoric acid, at $4^{\circ} \mathrm{C}$ for $18 \mathrm{~h}$. Measuring the elastic modulus of each stick was done to confirm complete demineralization which was set at $5 \mathrm{MPa} .^{35}$

\subsection{Stiffness Evaluation (3-point flexure test)}

The initial stiffness of 30 demineralized dentin sticks was measured using three-point bending test. A $1000 \mathrm{~g}$ load cell testing machine (Vitrodyne 1000 , VA, USA) was used at a crosshead speed of $1 \mathrm{~mm} / \mathrm{min}$. Stress-strain curves were obtained from load-displacement curves. Elastic Modulus (E) was calculated using the following formula:

$$
\mathrm{E}=\mathrm{PL}^{3} / 4 b d^{3} \mathrm{D}
$$

where: $\mathrm{P}=$ load;

$\mathrm{L}=$ support span;

$\mathrm{d}=$ thickness of stick;

$\mathrm{b}=$ width of stick;

$\mathrm{D}=$ displacement (deformation).

Then, the demineralized sticks (10/group) were immersed in chitosan solution $(0.1 \mathrm{~mol} / \mathrm{L}$ acetic acid) for $1 \mathrm{~min}$ or $10 \mathrm{~min}$. The sticks were then rinsed with water, re-tested and the stiffness was calculated. Each stick served as its own control.

\section{Hydroxyproline Release Test (Collagen solubili- zation by endogenous dentin proteases):}

Incubation of demineralized dentin sticks in a buffer solution at $37^{\circ} \mathrm{C}$, results in loss of dry mass and decrease in stiffness. ${ }^{36}$ The loss of dry mass was due to the hydrolytic activity of endogenous proteases, present in dentin, causing solubility of hydroxyproline-containing collagen peptides. ${ }^{7,37}$ When cross-linking solutions, such as carbodiimide or glutaraldehyde, were used to treat these demineralized matrices, the loss of dry mass was significantly reduced. ${ }^{38-40}$

A total of 30 dentin sticks $(3 \times 0.5 \times 6 \mathrm{~mm})$ were prepared and completely demineralized as explained before. After demineralization and rinsing, the sticks (10/group) were immersed in water for $10 \mathrm{~min}$ or in chitosan solution $(0.1 \mathrm{~mol} / \mathrm{L}$ acetic acid $)$ for $1 \mathrm{~min}$ or $10 \mathrm{~min}$, rinsed and then stored in 0.5 $\mathrm{ml}$ of HEPES buffer solution (0.05 $\mathrm{M}, \mathrm{pH} 7.4)$ in vibrating sealed containers at 15 cycles/min for 1 week at $37{ }^{\circ} \mathrm{C}$. The HEPES solution contained 2.5 $\mathrm{mM} \mathrm{CaCl} \cdot 2 \mathrm{H}_{2} \mathrm{O}$ and $0.02 \mathrm{mM} \mathrm{ZnCl}$. After storage, $6 \mathrm{~N} \mathrm{HCl}$ was created by mixing $100 \mu \mathrm{L}$ of incubation media with an equal volume of $12 \mathrm{~N} \mathrm{HCl}$. At $118^{\circ} \mathrm{C}$ for $16 \mathrm{~h}$, the $6 \mathrm{~N} \mathrm{HCl}$ was used to hydrolyze the soluble collagen fragments into amino acids in sealed glass ampoules. The vials were then opened to vaporize the $\mathrm{HCl}$ in a vacuum desiccator whose bottom was covered by $\mathrm{NaOH}$ pellets to neutralize the $\mathrm{HCl}$. Finally, the dry residue was examined for hydroxyproline using a colorimetric method. ${ }^{41}$

\section{Statistical Analysis:}

Collected data were evaluated for normality by using Kolmogorov-Smirnov and Shapiro-Wilk normality tests. All data showed normal (parametric) distribution except for hydroxyproline release results which showed non-normal (non-parametric) distribution. Parametric data are shown as mean and standard deviation (SD) values while nonparametric data are presented as median and range values. For parametric data; two-way ANOVA test was used to evaluate the effect of treatment, storage time and their interaction on mean microtensile bond strength and nanoleakage. One-way ANOVA 
was used to compare stiffness of the 3 groups. Bonferroni's post-hoc test was performed for pairwise comparison when ANOVA test was significant. For non-parametric data; Kruskal-Wallis test was performed to compare between hydroxyproline release in the 3 groups. Dunn's test was used for pair-wise comparisons when Kruskal-Wallis test is significant. The significance level was set at $\mathrm{P}$ $\leq 0.05$. Statistical analysis was performed using IBM SPSS Statistics for Windows, Version 22.0. Armonk, NY: IBM Corp.

\section{RESULTS}

\section{Microtensile bond strength}

The microtensile bond strength values of the control and the chitosan groups at the 3 storage periods ( $24 \mathrm{~h}, 12$ mos and 24 mos) are presented in table 1 .

After 24 hours of water storage, there was no significant difference between microtensile bond strength values obtained by the chitosan and the control groups $(P$-value $=0.163)$. At both 12 and 24 mos of water storage; microtensile bond strength values of the control group were significantly lower than the chitosan group ( $P$-value $<0.001)$. For both treatment groups (control and chitosan groups), the $24 \mathrm{~h}$ groups showed significantly higher microtensile bond strength values than the 12 mos groups ( $P$-value $<0.001)$ and similarly the $12 \mathrm{mos}$ groups showed significantly higher microtensile bond strength values than the 24 mos groups.

\section{Nanoleakage}

Table 2 summarizes the changes in the silver nitrate nanoleakage $\%$ within the bonded interfaces of the 2 treatment groups (control and chitosan) at different storage periods ( $24 \mathrm{~h}, 12$ mos and $24 \mathrm{mos}$ ).

At $24 \mathrm{~h}$ storage period, there was no significant difference in nanoleakage values between the 2 treatment groups $(P$-value $=0.279)$, however at 12 mos and 24 mos periods, the chitosan group exhibited significant lower nanoleakage values than the control group $(P$-value $<0.001)$.

TABLE (1) The mean, standard deviation (SD) values and results of two-way ANOVA test for comparison between microtensile bond strength $(\mathrm{MPa})$ with different interactions of variables.

\begin{tabular}{|c|c|c|c|c|c|c|}
\hline \multirow[b]{2}{*}{ Time } & \multicolumn{2}{|c|}{ Control } & \multicolumn{2}{|c|}{ Chitosan } & \multirow{2}{*}{$\begin{array}{c}P \text {-value } \\
\text { (Between } \\
\text { groups) }\end{array}$} & \multirow{2}{*}{$\begin{array}{c}\text { Effect size } \\
\text { (Partial etc } \\
\text { squared) }\end{array}$} \\
\hline & Mean & SD & Mean & SD & & \\
\hline 24 hours & $44.7^{\text {Aa }}$ & 2.4 & $46.9^{\mathrm{Aa}}$ & 1.6 & 0.163 & 0.105 \\
\hline 12 months & $29.8^{\mathrm{Bb}}$ & 2.6 & $40.7^{\mathrm{Bc}}$ & 1.7 & $<0.001 *$ & 0.750 \\
\hline 24 months & $25.5^{\mathrm{Cd}}$ & 2.2 & $37.2^{\mathrm{Ce}}$ & 1.9 & $<0.001 *$ & 0.775 \\
\hline$P$-value (Within group) & \multicolumn{2}{|c|}{$<0.001^{*}$} & \multicolumn{2}{|c|}{$<0.001 *$} & & \\
\hline Effect size (Partial eta squared) & \multicolumn{2}{|c|}{0.911} & \multicolumn{2}{|c|}{0.709} & & \\
\hline
\end{tabular}

*: Significant at $P \leq 0.05$, upper case letters are used for comparison between groups within the same vertical column, while lower case letters are used for comparison between the groups within each horizontal row (n=4, four teeth contributed 15 sticks per tooth or 60 sticks per treatment/time group. The statistical units were teeth, not sticks). 
TABLE (2) The mean, standard deviation (SD) values and results of two-way ANOVA test for comparison between nanoleakage (\%) with different interactions of variables.

\begin{tabular}{|c|c|c|c|c|c|c|}
\hline \multirow[b]{2}{*}{ Time } & \multicolumn{2}{|c|}{ Control } & \multicolumn{2}{|c|}{ Chitosan } & \multirow{2}{*}{$\begin{array}{c}P \text {-value } \\
\text { (Between } \\
\text { groups) }\end{array}$} & \multirow{2}{*}{$\begin{array}{c}\text { Effect size } \\
\text { (Partial eta } \\
\text { squared) }\end{array}$} \\
\hline & Mean & $\mathrm{SD}$ & Mean & $\mathrm{SD}$ & & \\
\hline 24 hours & $51^{\mathrm{Ba}}$ & 3.6 & $48.3^{\mathrm{Ca}}$ & 2.8 & 0.279 & 0.065 \\
\hline 12 months & $84^{\mathrm{Ab}}$ & 3.4 & $56.5^{\mathrm{Bc}}$ & 3.8 & $<0.001^{*}$ & 0.878 \\
\hline 24 months & $87.8^{\mathrm{Ad}}$ & 3.2 & $62 \mathrm{Ae}$ & 3.6 & $<0.001 *$ & 0.863 \\
\hline$P$-value (Within group) & \multicolumn{2}{|c|}{$<0.001 *$} & \multicolumn{2}{|c|}{$<0.001 *$} & & \\
\hline Effect size (Partial eta squared) & \multicolumn{2}{|c|}{0.940} & \multicolumn{2}{|c|}{0.644} & & \\
\hline
\end{tabular}

*: Significant at $P \leq 0.05$, upper case letters are used for comparison between groups within the same vertical column, while lower case letters are used for comparison between the groups within each horizontal row (n=4).

In the control group, nanoleakage increased significantly after 12 mos when compared to the $24 \mathrm{~h}$ values $(P$-value $<0.001)$, however there was no significant difference between nanoleakage values after 12 mos and 24 mos. Regarding the chitosan group, there was a significant increase in nanoleakage between the three testing periods $(P$-value $<0.001)$.

\section{Stiffness of completely demineralized dentin:}

Figure 1 presents the stiffness values (MPa) of completely demineralized dentin sticks of control, chitosan 1 minute and chitosan 10 minutes groups. The stiffness values of the completely demineralized dentin, treated with Chitosan for 10 minutes, were significantly the highest $(P$-value $<0.001)$. Chitosan treatment for $1 \mathrm{~min}$ showed significantly lower stiffness values than 10 min chitosan application group, while the demineralized beams which were kept in water and were not treated with chitosan (control) showed significantly the lowest stiffness values $(P$-value $<0.001)$.

\section{Hydroxyproline Release Test:}

Figure 2 shows the median (range) values for hydroxyproline release; 9.8 (6.9-16.7), 1.1 (0.4- 5.8) and 0.8 (0.2-4.9) $\mu \mathrm{g} / \mathrm{mg}$ dentin for control, chitosan 1 minute and chitosan 10 minutes groups, respectively. Hydroxyproline release in the control group was significantly higher than both chitosantreated groups $(P$-value $<0.001)$, however, there was no significance difference between the amount of hydroxyproline released after chitosan treatment for 1 and $10 \mathrm{~min}$. 


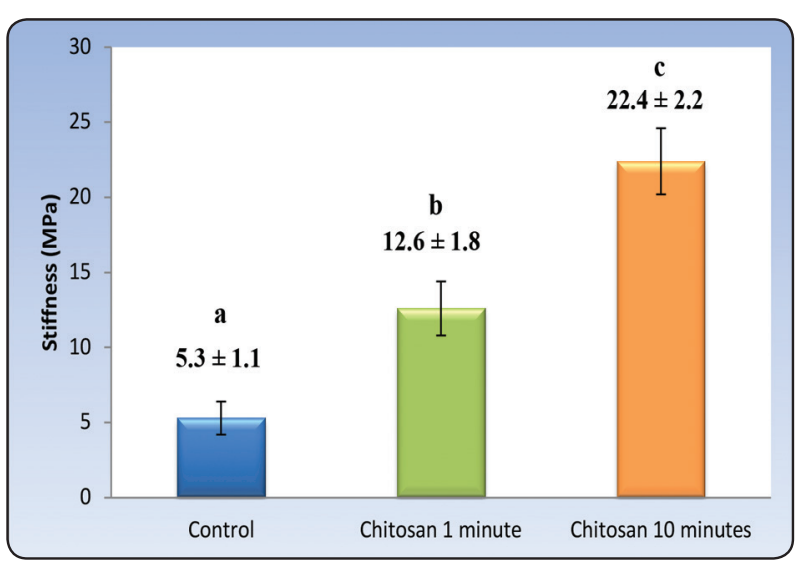

Fig. (1) Bar chart representing mean and standard deviation values for stiffness of the three groups $(n=10)$

\section{DISCUSSION}

During the last two decades, dentin adhesives have been well developed and have provided high initial bond strengths. Stability of dentin bonding is crucial for improving the lifetime of adhesive restorations..$^{1-4}$

The results of the current study demonstrated that microtensile bond strength and nanoleakage deteriorated significantly over a 2 year storage period. This was in accordance with many previous studies. ${ }^{1,3,6,16,30,36,42}$ Hybrid layer degradation has compromised the bonding stability of resin-dentin interfaces. ${ }^{2,42}$ Many factors were reported to be responsible for such degradation, ${ }^{1,2}$ including the degree of conversion ${ }^{43,44}$ and hydrophilicity ${ }^{45}, 46$ of adhesive resins, as well as the host-derived MMPs and cysteine cathepsins..$^{11-19}$

Hybrid layer degradation can occur due to ageing of one or more of its components, namely, dentin organic matrix or resin polymers. Resin and collagen present in hybrid layers may suffer from hydrolysis, thus increasing the water content at the interface, which adversely affect the longevity of the bond. ${ }^{1}$ Thus, there is a great relation between the degree of hydrophilicity of the adhesive, ${ }^{45}$ its water sorption capacity, ${ }^{47}$ and the subsequent degradation. Whatever the adhesive is, an etch-and-rinse or a self-

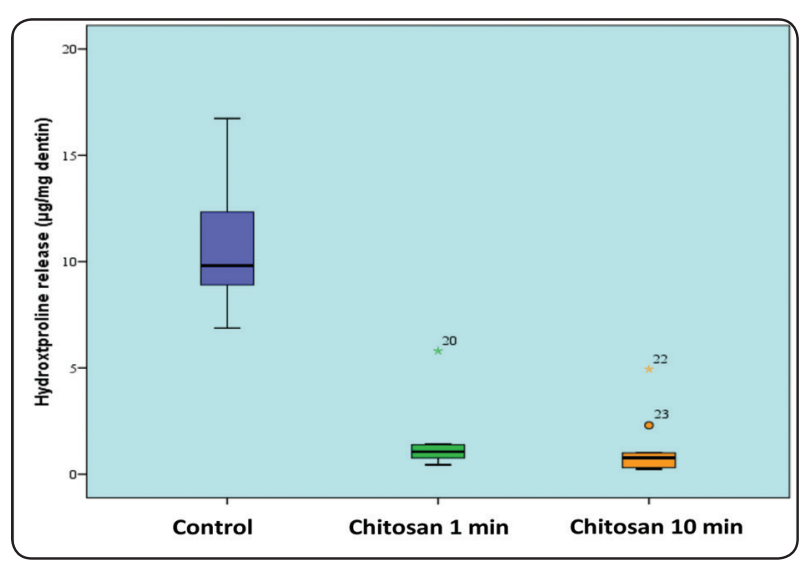

Fig. (2) Box plot representing median and range values for hydroxyproline release in the three groups (Stars and circle represent outliers, $n=10$ )

etch one, presence of hydrophilic monomers leads to the formation of highly permeable hybrid layers, even after adhesive polymerization. This allows continuous passage of water from the underlying dentin with subsequent increased nanoleakage and degradation of bonded interfaces. This phenomenon is very clear when using simplified adhesives, as they have a high percentage of hydrophilic monomers. ${ }^{45-47}$

Nanoleakage is a phenomenon referring to nanospaces that occurs within the hybrid layer, even in absence of interfacial gaps. Nanoleakage may result from improper adhesive resin penetration into the collagen network, incomplete solvent evaporation, unpolymerized monomers, or hydrolytic degradation of collagen and/or resin. An inverse correlation between bond strength and nanoleakage is expected since nanoleakage represents interfacial degradation which causes a decrease in the bond strength. ${ }^{16,34,43}$

When crosslinking agents are applied on acidetched dentin, they inactivate MMPs that are hydrolases. ${ }^{6,19,23,26-30}$ They also hinder the unwinding action of collagen triple helix which enables collagenases to cleave all polypeptides present in the collagen molecule, thus, increasing the hydrolytic degradation resistance of collagen. ${ }^{48}$ 
In the present study, when the acid-etched dentin was treated with chitosan solution $(0.1 \mathrm{~mol} / \mathrm{L}$ acetic acid) for $60 \mathrm{~s}$, prior to application of Adper Single Bond 2, no significant change has occurred in the $24 \mathrm{~h}$ microtensile bond strength and nanoleakage values. Accordingly, the first null hypothesis should be accepted which states that "chitosan treatment does not affect the immediate dentin bond strength and nanoleakage".

However, chitosan pre-treatment significantly improved the stability of the bonded interfaces over long-term storage periods (12 and 24 months). This was clear when compared to the control group, since it reduced the decrease in bond strength and significantly reduced the amount of nanoleakage in hybrid layers over time. Therefore, the results of this study require rejection of the second tested null hypothesis which states that "chitosan treatment does not affect the degradation of the resin-dentin interface over time".

Chitosan is a natural biopolymer that has the capacity to form microfibrillar and nanofibrillar network inside the protein matrix improving its mechanical properties. It is a biomimetic hydrophilic polymer that has free hydroxyl and amino groups that can form crosslinks with reactive molecules within the collagen fibrils resulting in marked increase in the stability of the collagen network. Also, chitosan is considered as a bioadhesive polymer due to its good muco-adhesive properties. ${ }^{28,30,49,50}$ Furthermore, Lobato et al in 2017 demonstrated the incorporation of chitosan in etch-and-rinse adhesive system to enhance antibacterial activity by means of ionic interactions between chitosan and the bacterial cells. ${ }^{32}$

In the current study, chitosan is used to cross-link and stiffen demineralized dentinal collagen to resist hydrolytic degradation over time, thus improving structural stability of resin-dentin interface. The ability of chitosan to preserve bond integrity was inferred in previous literature reports. ${ }^{28-32,49,50}$

On the other hand, Daood et al in 2013 stated that although chitosan has improved the structural stability of the demineralized dentin collagennetwork, exaggerated chitosan accumulation within collagen fibrils may hinder proper resin infiltration and results in defective hybrid layer formation. ${ }^{28}$

Crosslinkers increase the stiffness of collagen fibrils and consequently interferes with the ability of collagenases to unwind the collagen peptides. ${ }^{28-30}$ This effect was clear from the results of the current study that showed significant increase in stiffness when chitosan was used for 1 or $10 \mathrm{~min}$. Application of chitosan for 1 min raised the stiffness of completely demineralized dentin from $5.3 \mathrm{MPa}$ to $12.6 \mathrm{MPa}$, while when applied for $10 \mathrm{~min}$, the stiffness reached 22.4 MPa (Fig.1).

Since the acid-etched demineralized dentin layers is about $10 \mu \mathrm{m}$ thick, therefore the $0.5 \mathrm{~mm}$ (500 $\mu \mathrm{m})$ thick sticks, named macro-hybrid layer specimens ${ }^{51}$ used in the 3 -point flexure test, were 50 times thicker than reality. Thus, it can be speculated that it is much easier and faster to crosslink the $10 \mu \mathrm{m}$ demineralized dentin layers, that occur clinically, than crosslinking the $500 \mu$ m-thick beams that were used in the current study. Moreover, it is clear that 1 min of chitosan application on acid-etched dentin increased the stiffness of collagen fibrils much higher than their 5.3 MPa control values.

Decreased levels of hydroxyproline release in specimens treated by chitosan for 1 or $10 \mathrm{~min}$ when compared to control specimens demonstrate increased resistance of collagen to degradation by endogenous MMPs, these findings were in accordance with Zhou et al in $2016 .{ }^{48}$ These results support microtensile bond strength, nanoleakage and stiffness results of the present study.

To summarize, the performance of etch and rinse adhesives may improve greatly if preceded by chitosan application on acid-etched dentin. Crosslinking of demineralized collagen results in stiffening and improved mechanical properties which contribute to substantial stability of the bonded interfaces. However, the exact strengthening mechanism still needs to be further investigated. 
Crosslinking of dentinal collagen may allow going back to dry bonding. Previously, air-drying of demineralized dentinal surface caused collapse of exposed collagen fibers preventing proper resin penetration, thus, wet bonding was used instead since then. However, it is easier to remove water from etched-dentin before solvated adhesives are applied. Solvated adhesives reduce the vapor pressure of water, making it more difficult to evaporate from dentin. Strong air-drying after etching remove most of the free water thus reducing the possibility of phase separation that may take place when solvated adhesives are applied. Furthermore, removal of most of the water will reduce the possibility of presence of un-infiltrated exposed collagen within the hybrid layer that is highly susceptible to degradation. Dry bonding will also allow using more hydrophobic adhesives. ${ }^{47,48,51}$ Zhou et al in 2016, demonstrated promising results when cross-linking of acid-etched dentin was performed together with dry bonding, where no collagen collapse occurred. ${ }^{48}$ However, the merits of such combination should be further investigated before it can be implemented as a routine clinical procedure.

\section{CONCLUSIONS}

Chitosan treatment of acid-etched dentin, prior to adhesive application, was effective in improving durability of resin-dentin bonded interfaces. Future long-term in-vivo experiments on bond strength and nanoleakage should be performed to validate this finding.

\section{REFERENCES}

1. Breschi L, Mazzoni A, Ruggeri A, Cadenaro M, Di Lenarda R, De Stefano Dorigo E. Dental adhesion review: aging and stability of the bonded interface. Dental Materials 2008; 24:90-101.

2. Liu Y, Tjäderhane L, Breschi L, Mazzoni A, Li N, Mao J, et al. Limitations in bonding to dentin and experimental strategies to prevent bond degradation. Journal of Dental Research 2011; 90:953-968.
3. Shono Y, Terashita M, Shimada J, Kozono Y, Carvalho RM, Russell CM, et al. Durability of resin-dentin bonds. Journal of Adhesive Dentistry 1999; 1:211-8.

4. Hashimoto M. A review - micromorphological evidence of degradation in resin-dentin bonds and potential preventional solutions. Journal of Biomedical Materials Research: Part B, Applied Biomaterials 2010;92:268-80.

5. Loguercio AD, Moura SK, Pellizzaro A, Dal-Bianco K, Patzlaff RT, Grande RHM, et al. Durability of enamel bonding using two-step self-etch systems on ground and unground enamel. Operative Dentistry 2008; 33:79-88

6. Abu-Nawareg M, Abuelenain D, Elkassas D, Abu-Haimed T, Al-Dharrab A, Zidan A, Hassan A, Pashley D. The Role of Dentin Cross-Linking Agents in Optimizing Dentin Bond Durability. International Journal of Adhesion and Adhesives 2017; 78: 83-88.

7. Pashley DH, Tay FR, Breschi L, Tjaderhane L, Carvalho RM, Carrilho M, et al. State of the art etch-and-rinse adhesives. Dental Materials 2011; 27:1-16.

8. Botta SB). What causes durability reduction in toothcolored resin restorations? Journal of Contemporary Dental Practice; 2012; 13: i-ii.

9. Mazzoni A, Pashley DH, Tay FR, Gobbi P, Orsini G, Ruggeri A, et al. Immuno-histochemical identification of MMP-2 and MMP-9 in human dentin: correlative FEISEM/TEM analysis. Journal of Biomedical Materials Research A 2009; 88:697-703.

10. Mazzoni A, Pashley DH, Nishitani Y, Breschi L, Mannello F, Tjäderhane L, et al. Reactivation of inactivated endogenous proteolytic activities in phosphoric acidetched dentin by etch-and-rinse adhesives. Biomaterials 2006; 27:4470-4476.

11. Nishitani Y, Yoshiyama M, Wadgaonkar B, Breschi L, Mannello F, Mazzoni A, et al. Activation of gelatinolytic/ collagenolytic activity in dentin by self-etching adhesives European Journal of Oral Science 2006; 114:160-166.

12. De Munck J, Van den Steen PE, Mine A, Van Landuyt KL, Poitevin A, Opdenakker G, et al. Inhibition of enzymatic degradation of adhesive-dentin interfaces. Journal of Dental Research 2009; 88:1101-1106.

13. Osorio R, Yamauti M, Osorio E, Ruiz-Requena ME, Pashley D, Tay F, et al. Effect of dentin etching and chlorhexidine application on metalloproteinase-mediated collagen degradation. European Journal of Oral Sciences 2011; 119:79-85. 
14. Comba A, Maravic T, Valente L, Girlando M, Cunha SR, Checchi V, Salgarello S, Tay FR, Scotti N, Breschi L, Mazzoni A. Effect of benzalkonium chloride on dentin bond strength and endogenous enzymatic activity. Journal of Dentistry 2019; 85: 25-32.

15. Maravic T, Comba A, Cunha SR, Angeloni V, Cadenaro M, Visinitini E, Navarra CO, Salgarello S, Breschi L, Mazzoni A. Long-term bond strength and endogenous enzymatic activity of a chlorhexidine-containing commercially available adhesive. Journal of Dentistry 2019; 84: 60-66.

16. Abu-Naraweg M, Elkassas D, Zidan A, Abuelenain D, Abu-Haimed T, Akber AH, Chiba A, Bock T, Pashley DH. Is chlorhexidine-methacrylate as effective as chlorhexidine digluconate in preserving resin-dentin interfaces? Journal of Dentistry 2016; 45: 7-13.

17. Carrilho MR, Carvalho RM, de Goes MF, di Hipolito V, Geraldeli S, Tay FR, Pashley DH, Tjaderhane L. Chlorhexidine preserves dentin bond in vitro. Journal of Dental Research 2007; 86: 90-4.

18. Mazzoni A, Nascimento FD, Carrilho M, Tersariol I, Papa V, Tjäderhane L, Di Lenarda R, Tay FR, Pashley DH, Breschi L. Matrix metalloproteinase (MMP) activity in the hybrid layer detected with in situ zymography. Journal of Dental Research 2012;91: 467-472.

19. Bedran-Russo AK, Pereira PN, Duarte WR, Drummond JL, Yamauchi M. Application of crosslinkers to dentin collagen enhances the ultimate tensile strength. Journal of Biomedical Materials Research B Applied Biomaterials 2007; 80:268-272.

20. Bedran-Russo AK, Pashley DH, Agee K, Drummond JL, Miescke KJ. Changes in stiffness of demineralized dentin following application of collagen crosslinkers. Journal of Biomedical Materials Research B Applied Biomaterials 2008; 86:330-334

21. Bedran-Russo AK, Castellan CS, Shinohara MS, Hassan L, Antunes A. Characterization of biomodified dentin matrices for potential preventive and reparative therapies. Acta Biomaterialia 2011; 7:1735-1741.

22. Betancourt DE, Baldion PA, Castellanos JE. ResinDentin Bonding Interface: Mechanisms of Degradation and Strategies for Stabilization of the Hybrid Layer. International Journal of Biomaterials 2019; doi: $10.1155 / 2019 / 5268342$

23. Mazzoni A, Angeloni V, Apolonio FM, Scotti N, Tjaderhane L, Tezvergil-Mutluay A, De Lenarda R, Tay
FR, Pashley DH, Breschi L. Effect of carbodiimide (EDC) on the bond stability of etch and rinse adhesive systems. Dental Materials 2013; 29:1040-1047.

24. Castellan CS, Pereira PN, Grande RH, Bedran-Russo AK. Mechanical characterization of proanthocyanidin-dentin matrix interaction. Dental Materials 2010; 26:968-973.

25. Pashley DH, Agee KA, Nakajima M, Tay FR, Carvalho RM, Terada RS. Solvent-induced dimensional changes in EDTA-demineralized dentin matrix. J Biomed Mater Res 2001; 56: 273-281.

26. Snibson GR. Collagen cross-linking: a new treatment paradigm in corneal disease-a review. Clinical Experiment of Ophthalmolology 2010; 38:141-153.

27. Wollensak G, Spoerl E, Seiler T. Riboflavin/ultraviolet-ainduced collagen crosslinking for the treatment of keratoconus. American Journal of Ophthalmolology 2003; 135:620-627.

28. Daood U, Iqbal K, Nitisusanta L, Fawzy A. Effect of chitosan/riboflavin modification on resin/dentin interface: Spectroscopic and microscopic investigations. Journal of Biomedical Materials Research 2013; 101A (7): 18461856.

29. Fawzy A, Nitisusanta L, Iqbal K, Daood U, Beng L, Neo J. Chitosan/Riboflavin-modified demineralized dentin as a potential substrate for bonding. Journal of The Mechanical Behavior of Biomedical Materials 2013; 17: 278-289.

30. Daood U, Omar H, Tsoi J, Fawzy A. Long-term bond strength to dentine of a chitosan-riboflavin modified two step etch-and-rinse adhesives. International Journal of Adhesion and Adhesives 2018; 85: 263-273.

31. Gu LS, Cai X, Guo JM, Pashley DH, Breschi L, Xu HHK, Wang XY, Tay FR, Niu LN. Chitosan-Based Extrafibrillar Demineralization for Dentin Bonding. Journal of Dental Research 2019; 98(2): 186-193.

32. Lobato M, Turssi C, Do Amaral F, França F,Basting R. Chitosan incorporated in a total-etch adhesive system: antimicrobial activity against Streptococcus mutans and Lactobacillus casei. General Dentistry 2017; 62-66.

33. Shono Y, Ogawa T, Terashita M, Carvalho RM, Pashley EL, Pashley DH. Regional measurement of resin-dentin bonding as an array. Journal of Dental Research 1999; 78: 699-705.

34. Tay FR, Hashimoto M, Pashley DH, Peters MC, Lai SCN, Yiu CKY, Cheong C. Ageing affects two modes 
of nanoleakage expression in bonded dentin. Journal of Dental Research 2003; 82:537-41.

35. Carrilho MR, Tay FR, Donnelly AM, Agee KA, Tjäderhane L, Mazzoni A, et al. Host-derived loss of dentin matrix stiffness associated with solubilization of collagen. Journal of Biomedical Material Research B Applied Biomaterials 2009; 90: 373-80.

36. Sadek FR, Castellan CS, Braga RR, Mai S, Tjäderhane L, Pashley DH, et al. One-year stability of resin-dentin bonds created with a hydrophobic ethanol-wet bonding technique. Dental Materials 2010; 26: 380-6.

37. Tjäderhane L, Nascimento FD, Breschi L, Mazzoni A, Tersariol IL, Geraldeli S, et al. Strategies to prevent hydrolytic degradation of the hybrid layers-a review. Dental Materials 2013; 29: 999-1011.

38. Scheffel DL, Hebling J, Scheffel RH, Agee K, Turco G, de Souza Costa CA, et al. Inactivation of matrix-bound matrix metalloproteinases by cross-linking agents in acidetched dentin. Operative Dentistry 2014; 39: 152-8.

39. Scheffel DL, Hebling J, Scheffel RH, Agee KA, Cadenaro $\mathrm{M}$, Turco G, et al. Stabilization of dentin matrix after cross-linking treatments, in-vitro. Dental Materials 2014; 30: $227-33$

40. Tezvergil-Mutluay A, Mutluay MM, Agee KA, Seseogullari-Dirihan R, Hoshika T, Cadenaro M, et al. Carbodiimide cross-linking inactivates soluble and matrixbound MMPs, in-vitro. Journal of Dental Research 2012; 91:192-6.

41. Jamall IS, Finelli VN, Queltee SS. A simple method to determine nanogram levels of 4-hydroxyproline in biological tissue. Analytical Biochemistry 1981; 112:70-5.

42. Armstrong SR, Vargas MA, Chung I, Pashley DH, Campbell JA, Laffoon JE, Qian F. Resin-dentin interfacial ultrastructure and microtensile dentin bond strength after five year water storage. Operative Dentistry 2004; 29: 705-12.
43. Li H, Burrow MF, Tyas MJ. The effect of load cycling on the nanoleakage of dentin bonding systems. Dental Materials 2002; 18:111-119.

44. Abedin F, Ye Q, Parthasarathy R, Misra A, Spencer P. Polymerization behavior of hydrophilic-rich phase of dentin adhesive. Journal of Dental Research 2015; 94: 500-507.

45. Nishitani Y, Yoshiyama M, Donnelly AM, Agee KA, Sword J, Tay FR, Pashley DH. Effects of resin hydrophilicity on dentin bond strength. Journal of Dental Research 2006; 85:1016-1021.

46. Abu-Nawareg M, Zidan A, Zhou J, Chiba A, Tagami J, Pashley D. Adhesive sealing of dentin surfaces in vitro: A review. American Journal of Dentistry 2015; 28 (6): 321332.

47. Ito S, Hashimoto M, Wadgaonkar B, Svizero N, Carvalho RM, Yiu C, Rueggeberg FA, Foulger S, Saito T, Nishitani Y, Yoshiyama M, Tay FR, Pashley DH. Effects of resin hydrophilicity on water sorption and changes in modulus of elasticity. Biomaterials 2005; 26: 6449-59.

48. Zhou J, Chiba A, Scheffel DLS, Hebling J, Agee KA, Tagami J, Tan J, Abuelenain D, Abu-Nawareg M, Hassan AH, Breschi L, Tay FR, Pashley DH. Cross-linked dry bonding: a new etch-and-rinse technique. Dental Materials 2016; 32: 1124-1132.

49. Zhang J, Xia W, Liu P, Cheng Q, Tahirou T, Gu W, et al. Chitosan modification and pharmaceutical/biomedical applications. Marine Drugs 2010;8(7):1962-7.

50. Taravel MN, Domard A. Relation between the physicochemical characteristics of collagen and its interactions with chitosan: I. Biomaterials 1993; 14(12):930-8.

51. Pashley DH, Tay FR, Carvalho RM, Rueggeberg FA, Agee KA, Carrilho M, et al. From dry bonding to water-wet bonding to ethanol wet-bonding. A review of the interactions between dentin matrix and solvated resins using a macromodel of the hybrid layer. American Journal of Dentistry 2007; 20: 7-20. 